\title{
Design of Zero Voltage Switching Boost DC-DC Converter Using Bond Graph Model
}

\author{
Shaik Hussain Vali ${ }^{*}$, R Kiranmayi ${ }^{2}$ \\ ${ }^{1}$ Research Scholar, Electrical \& Electronics Engineering, JNT University, Anantapur, \\ India, \\ 2Professor, Electrical \& Electronics Engineering, JNT University, Anantapur, India, \\ Email: ${ }^{2}$ hussainvali4@gmail.com, ${ }^{2 k i r a n m a y i 0109 @ g m a i l . c o m ~}$ \\ *Corresponding Author: ${ }^{1}$ hussainvali4@gmail.com
}

Received June 6, 2020; Revised November 5, 2020; Accepted December 7, 2020

\begin{abstract}
The research in power supply design is moving towards improving efficiency by reducing losses. Another aspect of research in power converters is its modeling as it involves multiple domains such as electrical, mechanical, magnetic...etc. bond graph modeling is suitable for the multi domain systems. Here, a zero voltage switching boost converter is designed using its bond graph model. The bond graph simulated results which are done in MATLAB/SIMULINK are matched with the experimental results. The developed bond graph model results are compared with experimental results. The efficiency of the ZVS boost converter is calculated and is compared with the efficiency of conventional pulse width modulated (PWM) boost converter.
\end{abstract}

Keywords: bond graph, boost converter, pulse width modulation, zero voltage switching.

\section{INTRODUCTION}

The efficiency of a power converter plays a major role in the size and power density of the system. Research continued in enhancing the efficiency. Pulse width modulated converters are being used widely to meet the demands [1]. Even though the operational efficiency is higher, still there are several bottle necks in them. Switching phenomenon is hard, leading to several problems such as power loss, stress...etc. The switching phenomenon may be made smooth by adding extra circuitry. This extra circuit will make the switching process smooth and soft which in turn limits the switching problems. They exhibit resonance during switching phenomenon [2]. The resonance make the switching variables sinusoidal and has the possibility to have zero instant values which are classified as zero voltage switching or zero current switching. 


\section{RELATED WORKS}

For a good design, the system must be modeled accurately. There are some models such as switched state space model, state space average model, circuit averaging model, generalized average model and sampled data models [3] for power electronic converters. State space model of non isolated DC-DC boost converter has been developed in literature [4]. The converter switches, inductors and capacitors are to be modelled based on the simulation type chosen. So, the modeling and the program are different for different applications [5]. Some fast algorithms used to simulate the power electronic systems by making the complex equations into simple simple algebraic equations and simulated. But the systems become more simple [6]. Analogous electrical terms are used for modeling multi domain system [7]. But the difficulty is going back and forth into original system after modeling. Bond graph modeling [7]-[8] has the ability to solve this problem. Bond graph modeling is most suitable because the systems involve more than one domain other than electrical domain such as thermal magnetic...etc. bond graph modeling has a unique and simple procedure for multiple domains.

\section{ORIGINALITY}

Here, the originality is design of zero voltage switching boost converter using the developed bond graph model. The procedure in the bond graph modeling is first to divide the entire system into sub systems based on the domain type. Every sub system is represented graphically called bond graph which has magnitudes and directions [8]. All the bond graphs of the sub systems are joined and made into a single bond graph. This is possible because bond graphs do not depend on the domain. Irrespective of the domain, the power of signal which is the product of effort and flow is common to all domains. In bond graph modeling, it is not necessary to convert the non electrical domains into its analogous electrical domains. An example is given in Appendix-A. By maintaining proper causality and basic principles of the domains, the equations are derived and used for the simulations and further hardware design. In power electronic systems, there is different situation arise as the systems energy levels vary with the change in states of the systems. The systems have power semiconductor devices which are in the forms of switches which changes the switching states from $\mathrm{ON}$ to OFF and vice versa. So, the bond graphs vary with the changes every time. Switched power junctions [9] are vastly utilized in modeling these types of systems. An example is given in Appendix-B.

\section{SYSTEM DESIGN}

\subsection{CONVERTER MODELLING}

The zero voltage switching boost DC-DC converter [10] is drawn as in figure 1 below. The conventional PWM boost converter has an additional 
inductor and a capacitor which arranged as below so that they create resonance during switching process.

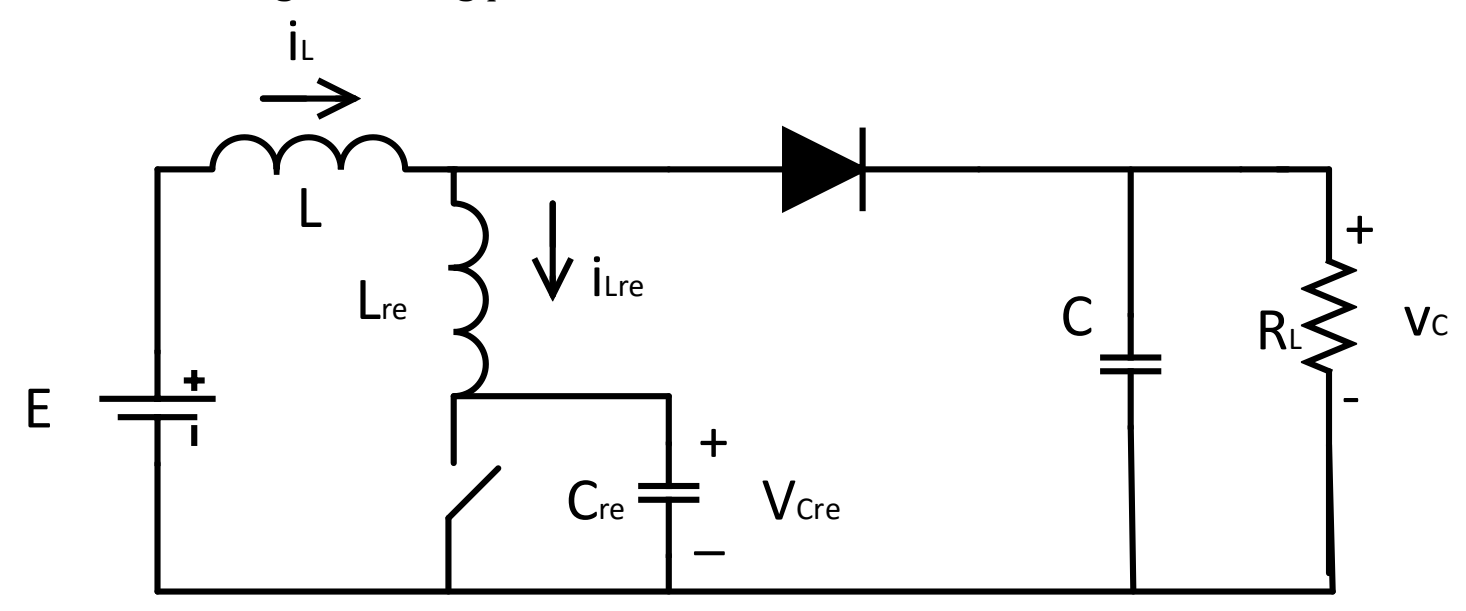

Figure 1. Zero voltage switching boost DC-DC Converter

The bond graph models of the converter [11] for different situations are given from figures 2(a) - 2(c). They are large signal model, steady state signal model and small signal AC bond graph models respectively. By following the basic electrical principles such as kirchoff's laws and causality principles, the equations obtained are as follows (1)-(4). In figures 2(a) - 2(c), there are bonds and junctions. At 1-junction, the current is same in all bonds attached to the junction. Whereas the algebraic sum of voltages at the 1-junction is zero by taking the voltage polarity of bonds going away from the junction are opposite to that of bonds coming towards the junction. At 0 -junction, the voltage is same in all bonds attached to the junction. Whereas the algebraic sum of currents at the 0 -junction is zero by taking the current polarity of bonds going away from the junction are opposite to that of bonds coming towards the junction [8].

For example: From figure 2(b), as per the rule mentioned above, the voltage across ' $\mathrm{L}$ ', is ( $\mathrm{E}$ - the voltage on the bond right side). $\mathrm{V}_{\mathrm{L}}=\mathrm{E}-\mathrm{V}_{1}$. The voltage $\mathrm{V} 1$ is equal to the voltage of first 0 -juntion adjacent to the 1 -junction. The voltage of first 0 -juntion $=$ the voltage of second 0 -juntion + the voltage across Rsoff The voltage of second 0 -juntion $=V_{c}=V_{0}$. The voltage across $R_{\text {soff }}=($ Current in $\left.R_{s o f f}\right) R_{s o f f} U_{4}$. Applying the rule at first 0 -juntion Current in $R_{s o f f}=$ (IL - ILre) By substituting all these, we will get equation (2) $V_{L}=E$-( $\left.I_{L}-I_{L r e}\right) R_{s o f f} U_{4}-V_{o}$

Similarly, the remaining equations are obtained. From these equations, the parameters are selected by considering the steady state conditions for the given input and output voltages.

$$
\begin{aligned}
& v_{\text {Lre }}=v_{C r e} U_{2}-R_{\text {soff }} U_{4}\left(i_{\text {Lre }}-i_{L}\right)+v_{0} \\
& v_{L}=U_{4}\left(i_{\text {Lre }}-i_{L}\right) R_{\text {soff }}-v_{0}+E
\end{aligned}
$$




$$
\begin{aligned}
& i_{\text {Cre }}=i_{\text {Lre }} U_{2} \\
& i_{C}=-\frac{v_{0}}{R_{L}}-\left(i_{\text {Lre }}-i_{L}\right) U_{3}
\end{aligned}
$$

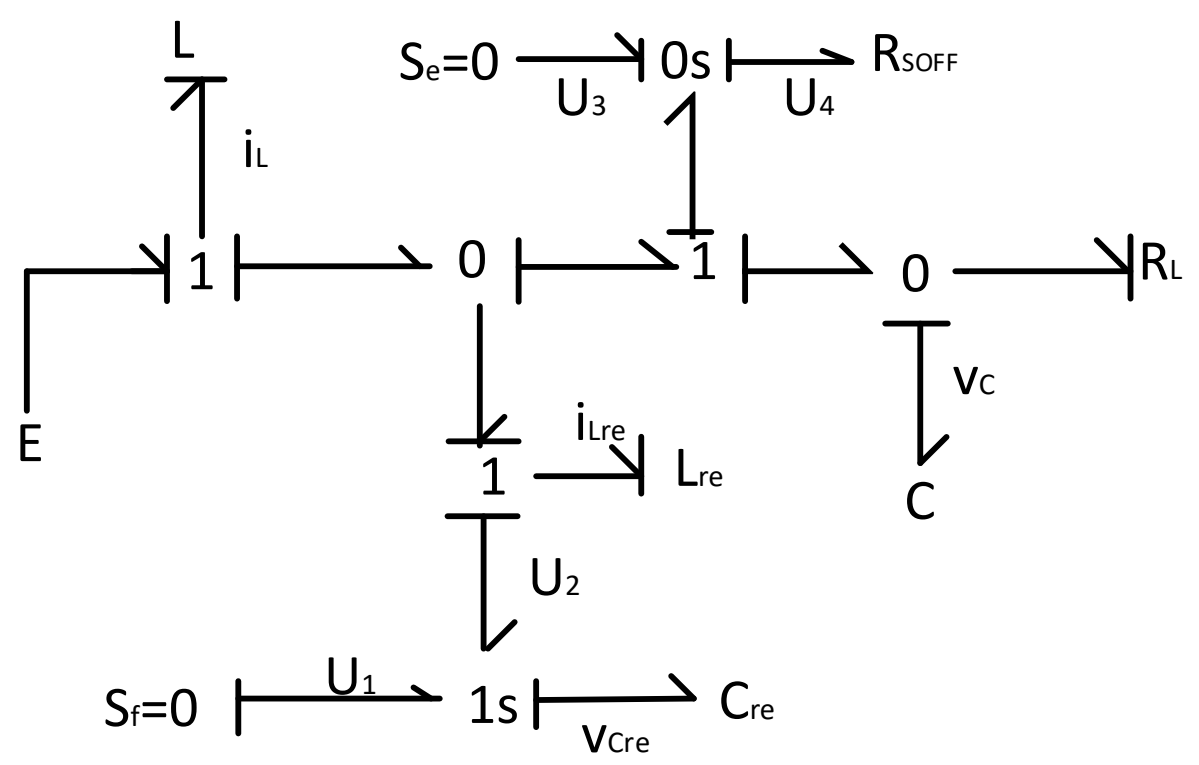

Figure 2(a). Large signal Bond graph model of ZVS boost DC-DC converter

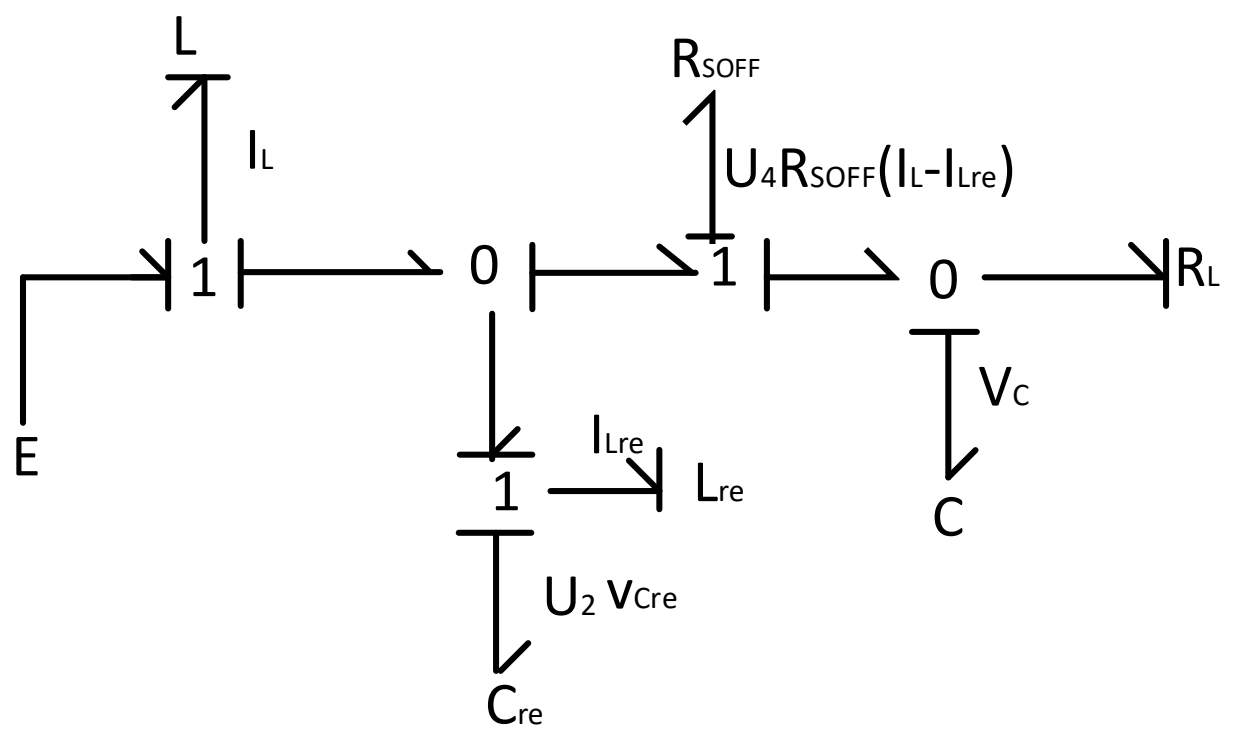

Figure 2(b). Steady state Bond graph model of ZVS boost DC-DC converter 


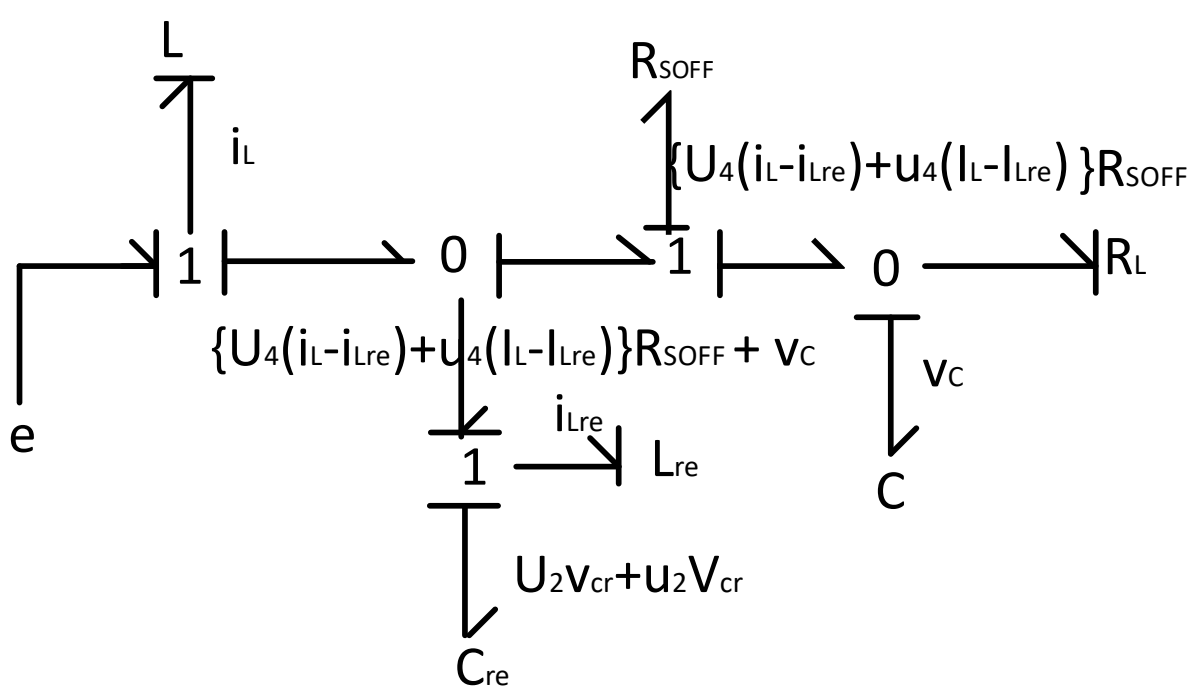

Figure 2(c). Small-signal AC Bond graph model of ZVS boost DC-DC converter

Where the suffix 'Lre' represents the resonant inductor variables and ' $\mathrm{Cre}_{\mathrm{re}}$ ' represents resonant capacitor variables. $\mathrm{U}_{1}-\mathrm{U}_{4}$ represents the various states. $\mathrm{R}_{\text {soff }}$ is a large resistor in place of a reverse biased diode to maintain the causality.

\subsection{CONVERTER DESIGN}

For the given values of battery voltage $(E)$, Resistance $\left(R_{L}\right)$ and output voltage $\left(V_{c}\right)$, the design is as follows. The interrelationship between output and input voltages are given by (5) in which ' $d$ ' represents the duty cycle. The converter inductance (L) and the converter capacitance (C) are depending on the limits of current and voltage ripples respectively [12]. The resonant components are chosen in such a way their values are much smaller than the converter components to have higher value of resonant frequency ( $f_{0}$ ) [13]. They are given from (6)-(10). Using the above equations, the values obtained are presented in Table 1.

$$
\begin{aligned}
v_{C} & =\frac{E}{1-d} \\
L & =\frac{d(1-d)^{2} R T_{S}}{\% \text { ripple }_{\text {current }}} \\
C & =\frac{d T_{S}}{\left(\% \text { ripple }_{\text {voltage }}\right) R} \\
f_{0} & =\frac{V_{c} f_{s}}{1.1 E} \\
L_{r} & =\frac{R_{L} E}{2 \pi f_{0} V_{C}}
\end{aligned}
$$




$$
C_{r}=\frac{V_{C}}{2 \pi f_{0} E R_{L}}
$$

Using the said equations, the obtained values are presented in Table 1

Table 1. Converter parameters

\begin{tabular}{|c|c|}
\hline Parameter & Value \\
\hline Input Battery Voltage $(\mathrm{E})$ & $10 \mathrm{~V}$ \\
\hline Output Voltage $\left(\mathrm{V}_{\mathrm{c}}\right)$ & $20 \mathrm{~V}$ \\
\hline Resistance $\left(\mathrm{R}_{\mathrm{L}}\right)$ & $100 \Omega$ \\
\hline Switching frequency $\left(\mathrm{f}_{\mathrm{s}}\right)$ & $20 \mathrm{kHz}$ \\
\hline Resonant frequency $\left(\mathrm{f}_{\mathrm{o}}\right)$ & $36.363 \mathrm{kHz}$ \\
\hline Circuit inductance $(\mathrm{L})$ & $>62.5 \mathrm{mH}$ \\
\hline Circuit capacitance $(\mathrm{C})$ & $>25 \mu \mathrm{F}$ \\
\hline Resonant Inductor $\left(\mathrm{L}_{\mathrm{re}}\right)$ & $218.83 \mu \mathrm{H}$ \\
\hline Resonant Capacitance $\left(\mathrm{C}_{\mathrm{re}}\right)$ & $87.53 \mathrm{nF}$ \\
\hline
\end{tabular}

\section{SIMULATED RESULTS}

The developed bond graph models are converted into MATLAB tools using a toolbox [14] and for the above tabulated values; simulated pictures are from figures $3(a)-3(b)$.

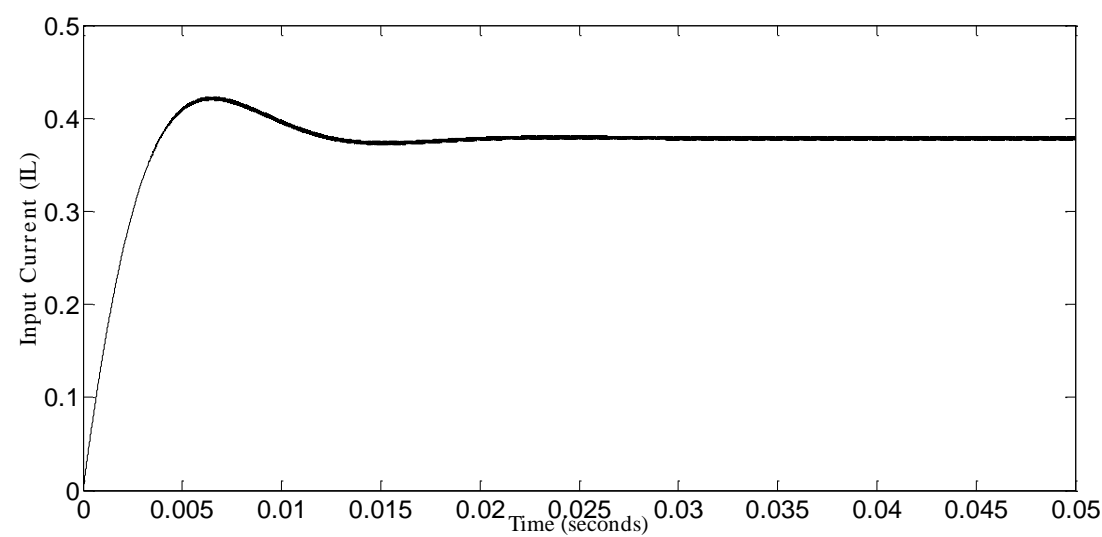

Figure 3(a). Inductor Current $\left(\mathrm{I}_{\mathrm{L}}\right)$ - ZVS boost DC-DC Converter

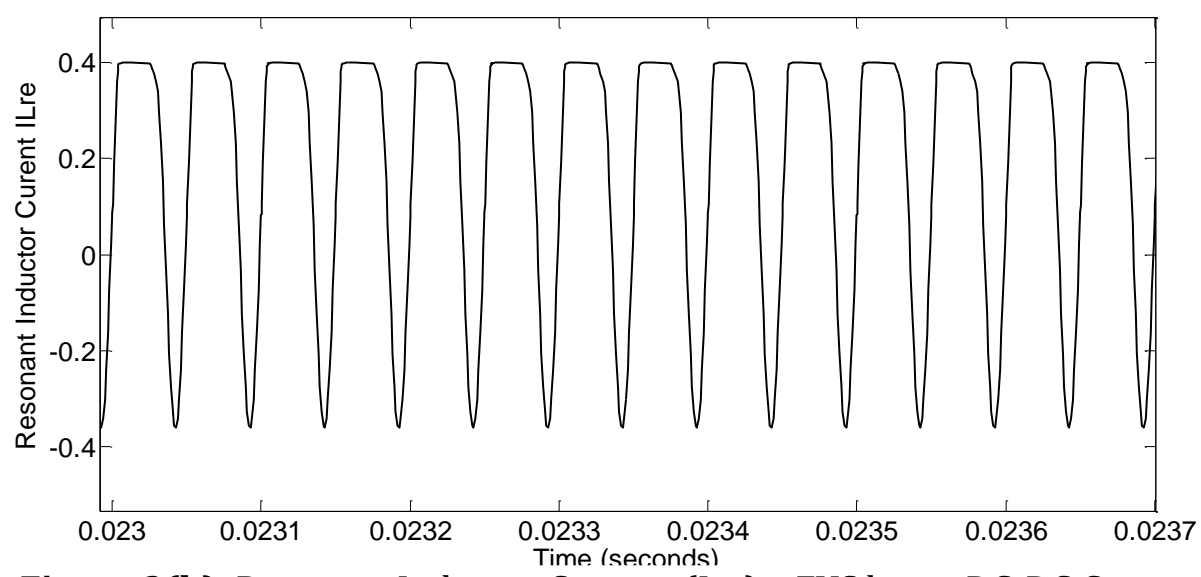

Figure 3(b). Resonant Inductor Current ( $\left.\mathrm{I}_{\text {Lre }}\right)$ - ZVS boost DC-DC Converter 


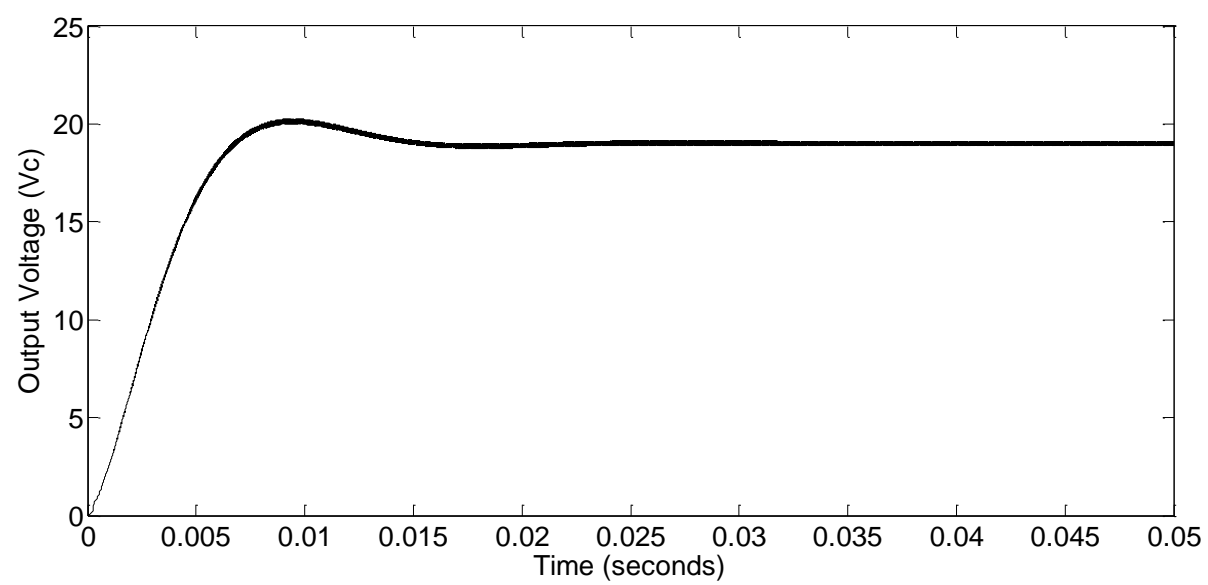

Figure 3(c). Output voltage $\left(\mathrm{V}_{\mathrm{c}}\right)$ - ZVS boost DC-DC Converter

From the figure $3(\mathrm{a})$, it is found that the average value of inductor current is 0.38 A. From figure $3(\mathrm{~b})$, the maximum - maximum value of resonant inductor current is $0.75 \mathrm{~A}$ and its frequency is $20 \mathrm{kHz}$. From figure 3 (c), the average value of load voltage is $18 \mathrm{~V}$. From figure $3(\mathrm{~d})$, the maximum value of resonant capacitor voltage is $38 \mathrm{~V}$ and its frequency is 20 $\mathrm{kHz}$. These values are in coordination with the state equations theoretically.

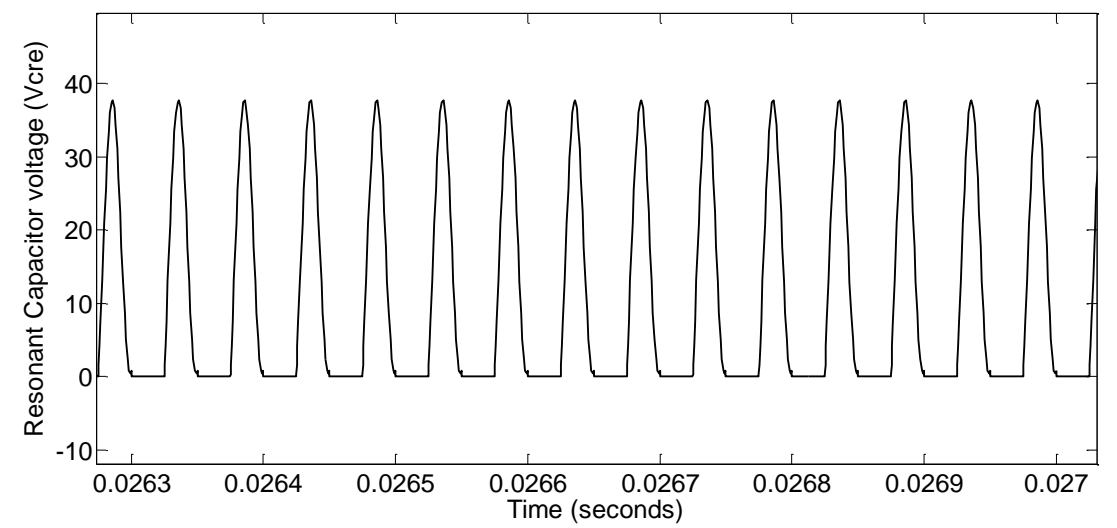

Figure 3(d). Resonant capacitor voltage (Vcre) - ZVS boost DC-DC Converter

\section{EXPERIMENT AND ANALYSIS}

\subsection{GATE PULSE GENERATION}

The hardware is designed with tabulated values. The switching pulses are obtained from IC555 timer under astable mode of operation. The corresponding circuit is in figure 4(a) below. 


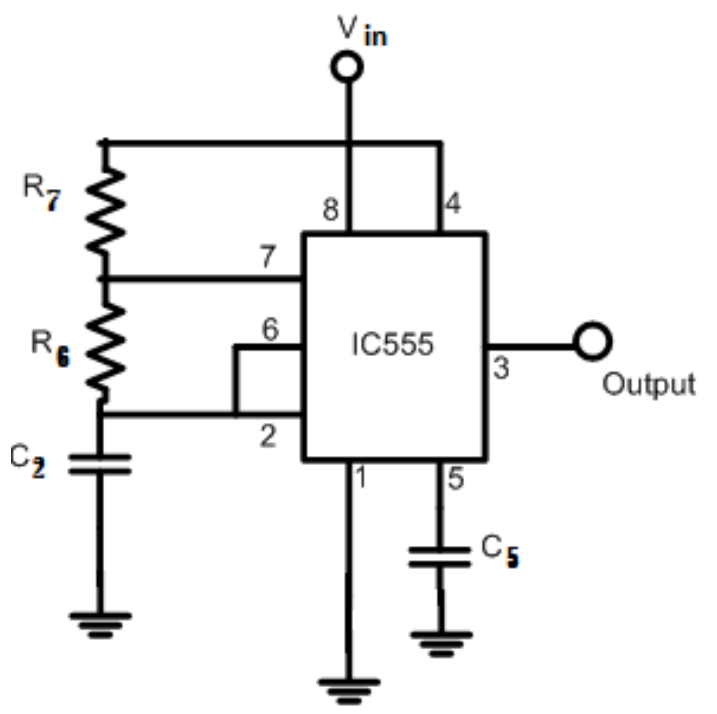

Figure 4(a). Generation of switching pulses with IC555

The expressions for turn ON and turn OFF times, the switching period and the duty cycle are respectively from (11) - (14). By taking $\mathrm{C}_{1}=\mathrm{C}_{2}=10 \mathrm{nF}$ and by varying the rheostats $\mathrm{R}_{6}$ and $\mathrm{R}_{7}$, different frequencies and different duty cycle pulses can be generated.

$$
\begin{aligned}
& t_{\text {on }}=0.693\left(R_{6}+R_{7}\right) C_{2} \\
& t_{\text {off }}=0.693 R_{6} C_{2} \\
& T_{s}=\left(t_{\text {on }}+t_{\text {off }}\right) \\
& d=\left(\frac{R_{7}+R_{6}}{R_{7}+2 R_{6}}\right) * 100 \%
\end{aligned}
$$

The switching pulses generation hardware set up is shown below in figure 4(b). The IC is being supplied from a $9 \mathrm{~V}$ battery. The generated pulses are fed to the switch in the converter. The pulse with $50 \%$ duty cycle is given below in figure $4(\mathrm{c})$.

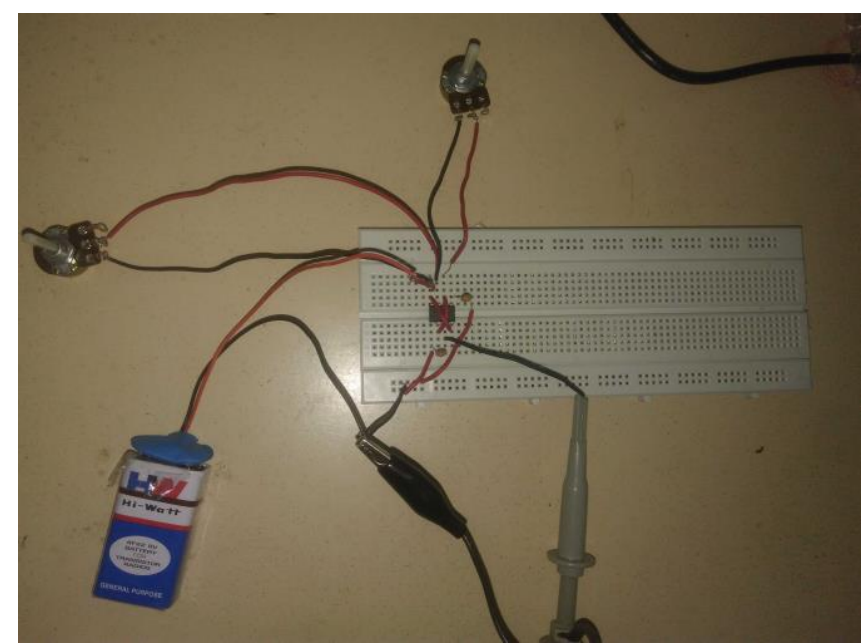

Figure 4(b). Hardware set up to generate gate pulses 


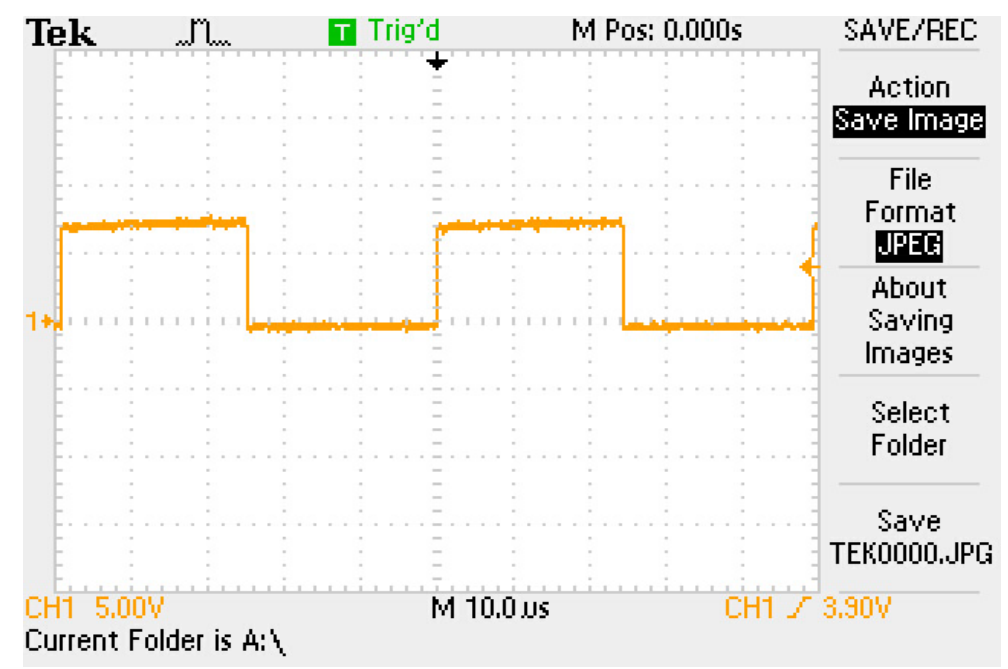

Figure 4(c). Pulse from the pulse generated circuit with 50\% duty ratio

\subsection{ZVS BOOST DC-DC CONVERTER}

The switching pulses generation circuit and the converter circuit are assembled and is shown in figure 5. The entire hardware setup includes measuring instruments as well. With the selected parameters, the plots using CRO are drawn in figures 6(a) to 6(d) which are respectively source current ( $\mathrm{L}_{\mathrm{L}}$ ), Resonant Inductor current (ILre), load voltage $\left(\mathrm{V}_{\mathrm{C}}\right.$ ) and Resonant capacitor voltage $\left(\mathrm{V}_{\text {cre }}\right)$ waveforms.

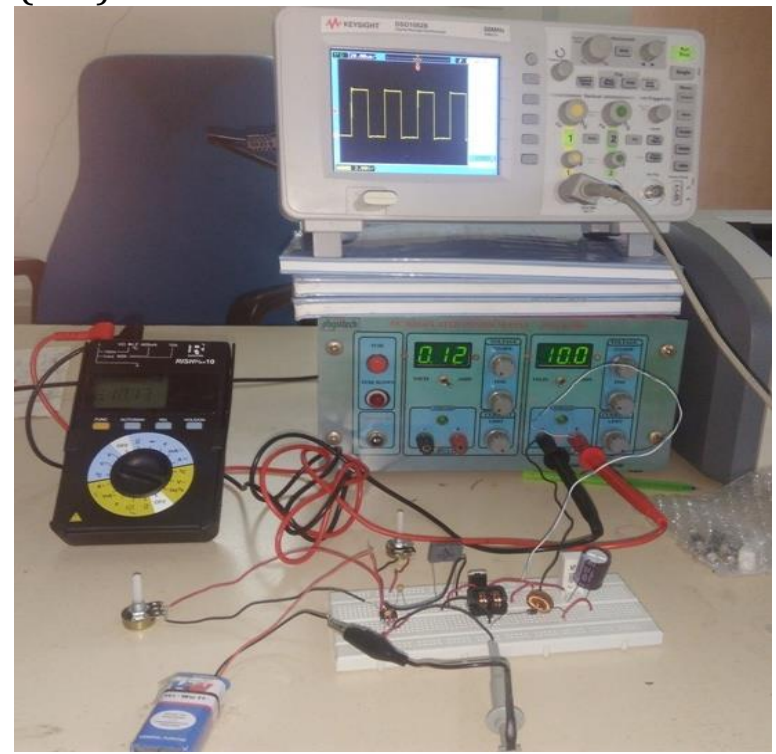

Figure 5. Hardware of zero voltage switching boost DC-DC converter 


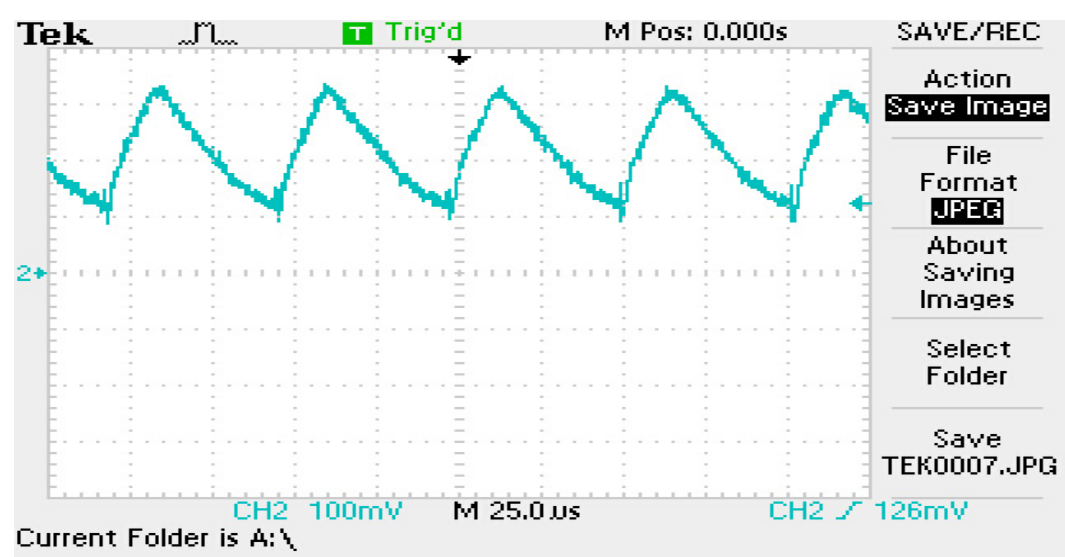

Figure 6(a). Source/Inductor Current $\left(\mathrm{I}_{\mathrm{L}}\right)$

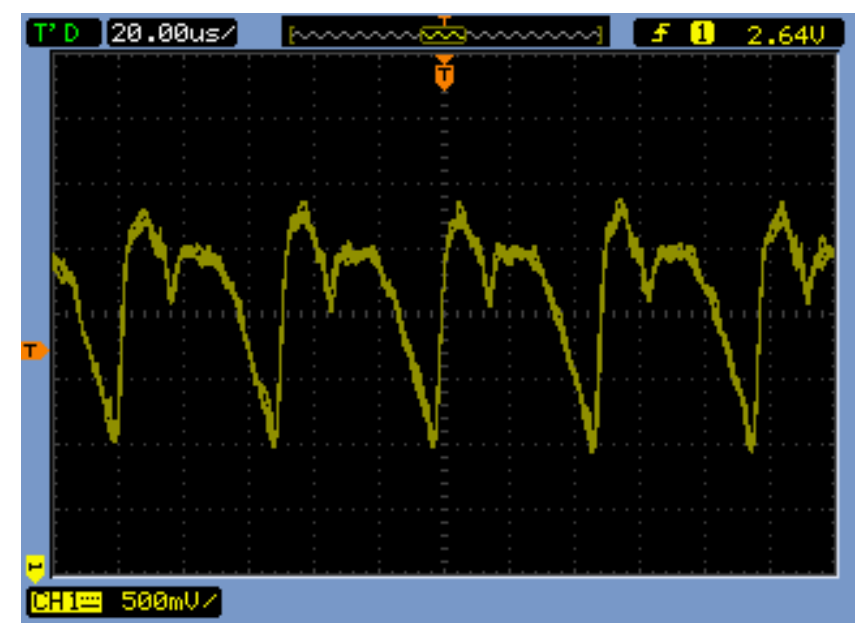

Figure 6(b). Resonant Inductor Current ( $\left.\mathrm{I}_{\text {Lre }}\right)$

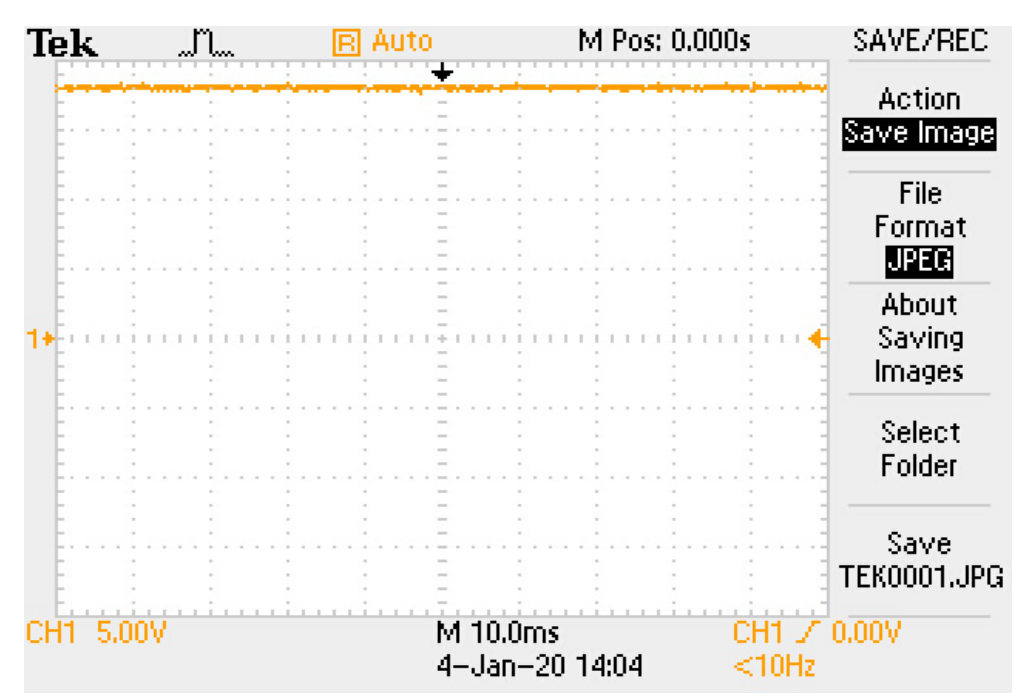

Figure 6(c). Load/output Voltage $\left(\mathrm{V}_{c}\right)$ 


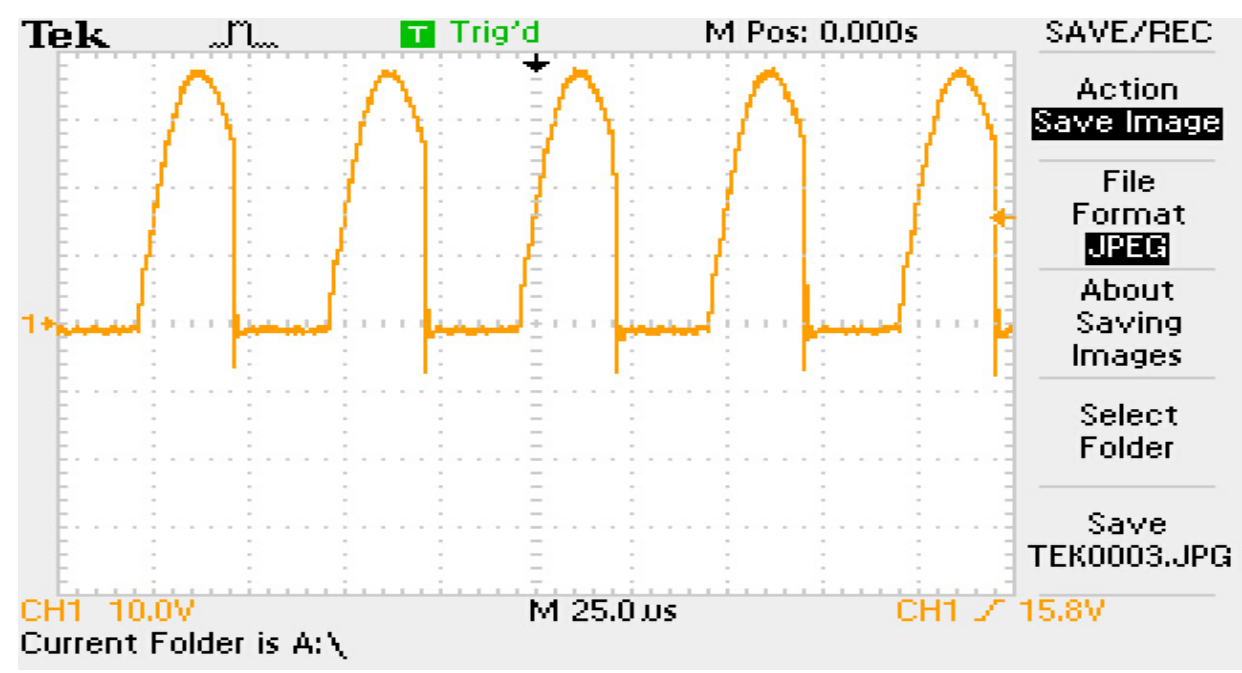

Figure 6(d). Resonant Capacitor Voltage (Vcre) of ZVS Boost Converter

Using a current probe, the inductor current $\left(\mathrm{I}_{\mathrm{L}}\right)$ or the source current of the boost ZVS DC-DC converter is calculated. The current probe is set at 100 $\mathrm{mV} / \mathrm{A}$. Based on the setting and number of conductors clamped in current probe, the source current is found to be $0.36 \mathrm{~A}$ on an average. Using a HO-P current sensor, the plot of resonant inductor current waveform ( $\mathrm{I}_{\text {Lre }}$ ) is given in figure 6(b). Based on the setting and number of conductors clamped, the value of ( $\mathrm{I}_{\text {Lre }}$ ) is $0.76 \mathrm{~A}$. The average load voltage of the converter is calculated to be $18 \mathrm{~V}$ from figure $6(\mathrm{c})$. The maximum value of resonant capacitor voltage is calculated to be $37 \mathrm{~V}$ from figure $6(\mathrm{~d})$. The efficiency of the converter is nothing but the ratio of output power to input power. The output power is nothing but the product of output voltage and output current. Hence the output power from the calculations is $3.24 \mathrm{~W}$ where as the input power from the calculations is $3.6 \mathrm{~W}$. So, the efficiency is $90 \%$.

\subsection{CONVENTIONAL PWM BOOST DC-DC CONVERTER}

The Hardware of the conventional boost converter without any resonant techniques is given below in figure $7(\mathrm{a})$.

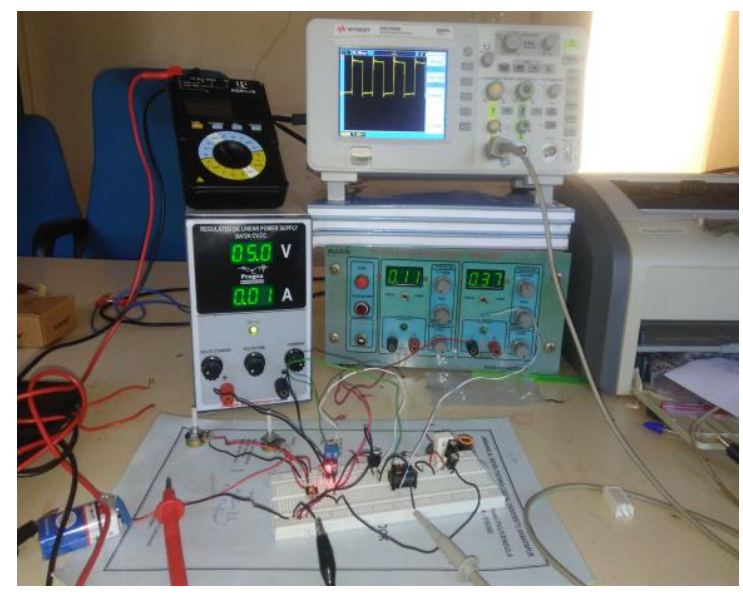

Figure 7(a). Hardware of conventional Boost Converter 
The input current and output voltage waveforms are drawn in figures 7(b) and 7(c) respectively.

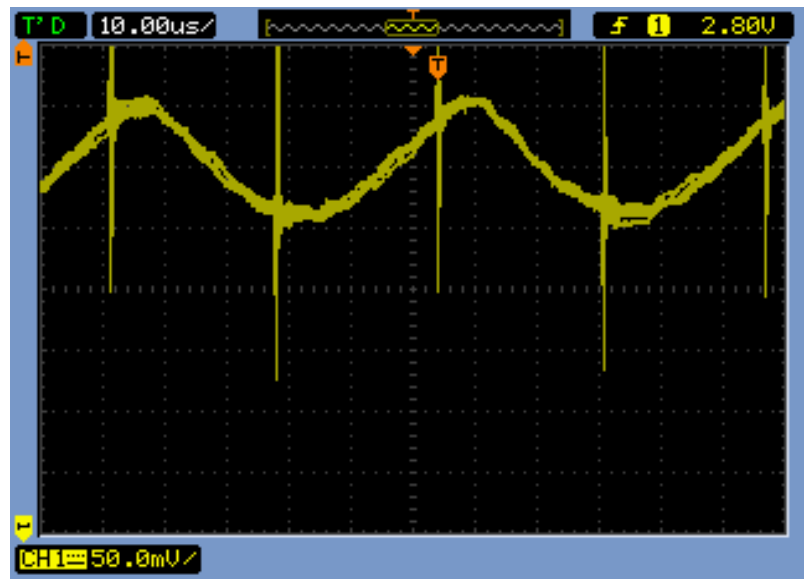

Figure 7(b). Input/inductor current of conventional Boost Converter

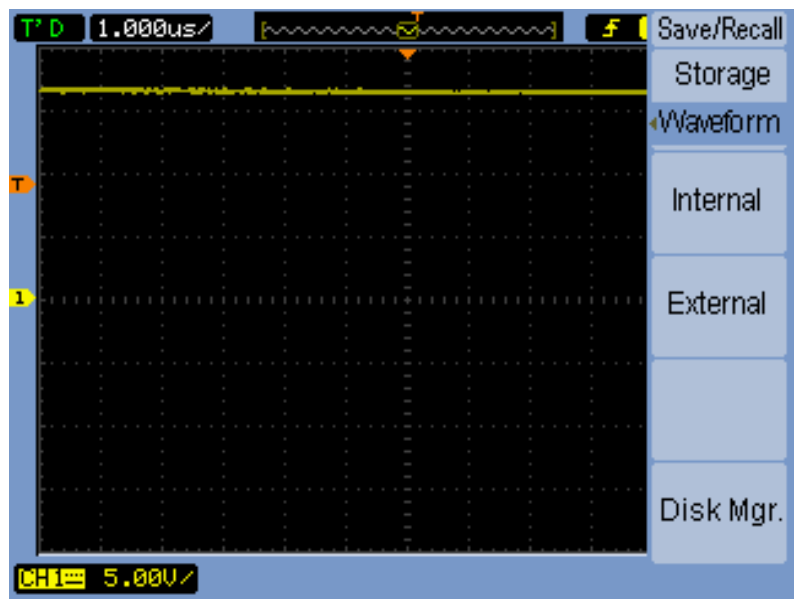

Figure 7(c). Output/load voltage of conventional Boost Converter

The input current in the conventional boost DC-DC converter is measured using the current sensor. The average value of input current being calculated as $0.37 \mathrm{~A}$ as in figure $7(\mathrm{~b})$. The DC value of output voltage is measured to be $17 \mathrm{~V}$ which is obtained by averaging the plot. The output/load power of the converter is calculated from the output variables as $2.89 \mathrm{~W}$. The source/input power is calculated from the input variables and is $3.7 \mathrm{~W}$. So, the efficiency is calculated as $78.1 \%$. The efficiency of this conventional boost converter is lesser when in comparison with ZVS converter $(90 \%)$. The reason for this is due to the presence of more switching losses in the conventional converter. The conduction and blocking losses in both the converters may be same approximately. The experimental results from the hardware setup and the bond graph model results in simulation are presented in Table 2, they are satisfying each other. 
Table 2. Results - zero voltage switching boost DC-DC Converter

\begin{tabular}{|c|c|c|}
\hline & MATLAB/SIMULINK & Experminetal \\
\hline Inductor Current $\left(\mathrm{I}_{\mathrm{L}}\right)$ (Average) & $0.38 \mathrm{~A}$ & $0.36 \mathrm{~A}$ \\
\hline $\begin{array}{c}\text { Peak-Peak Value of Resonant } \\
\text { Inductor Current }\left(\mathrm{I}_{\text {Lre }}\right)\end{array}$ & $0.75 \mathrm{~A}$ & $0.76 \mathrm{~A}$ \\
\hline Average load voltage $\left(\mathrm{V}_{\mathrm{c}}\right)$ & $18 \mathrm{~V}$ & $18 \mathrm{~V}$ \\
\hline $\begin{array}{c}\text { Peak-peak Resonant Capacitor } \\
\text { Voltage }\left(\mathrm{V}_{\text {cre }}\right)\end{array}$ & $38 \mathrm{~V}$ & $37 \mathrm{~V}$ \\
\hline
\end{tabular}

\section{CONCLUSION}

In this piece of work, experimental verification of the bond graph model of boost ZVS DC-DC converter is done. The waveforms of inductor currents and the capacitor voltages are plotted. Their response is analysed both in simulation and experimentally. Simulation is done in MATLAB/SIMULINK. The power efficiency of the converter is calculated and is found to be $90 \%$ and is found to be more than the power efficiency which is $78.1 \%$ in case of conventional PWM boost converter without any resonant techniques. This is due to the reduction in switching losses in zero voltage switching techniques. The verified bond graph model is applicable in any applications of either similar domain or other non electrical domains due to the advantages of multi-domain applications of bond graph models. This technique reduces the efforts of finding analogous models of the physical systems.

\section{Acknowledgements}

Authors would like to appreciate the Jawaharlal Nehru Technological University Anantapur (JNTUA), India for its support to do it.

\section{REFERENCES}

[1] Marian K. Kazimeirczuk, Pulse Width Modulated DC-DC Power Converters, John Wiley \& Sons, 2nd Edition, 2016.

[2] GHua and F.CLee, Softswithing techniques in PWM converters, IEEE Transactions on Industrial Electronics, Vol. 42, No. 6, pp. 595-603, 1995.

[3] D. Maksiimoivic, A. M.Stankooviic, V. J. Totuuveli and G. C.Verghese, Modeling and simulation of power electronic converters, Proceedings of IEEE, Vol. 89, No. 6, pp. 898-912, 2001.

[4] Modabbernia, M.R., Akoushideh, A., \& Fakhrmoosavi, S.Y., Design and analysis of the voltage controller for the non isolated boost DC-DC converter, EMITTER International Journal of Engineering Technology, Vol. 7, No. 1, pp. 14-33, 2019.

[5] N.Mohan, W.Robbins, TM.Undeland, R.Nilsen and O.Mo, Simulation of power electronics and motion control systems:an overview, Proceedings of the IEEE, Vol. 82, No. 8, pp. 1287-1302, 1994.

[6] Henry Chung and Adrain Ioinavici, Fast ComputerAided Simulation of Switching PowerRegulators Based on Progresive Analysis of the 
Switch's State, IEEE Transections on Power Electornics, Vol. 9, No. 2, pp. 206-212, 1994.

[7] D. C Karnopp, D. LMargolis and R. CRosenberg, System Dynamics: A Unified Approach, John Wiley \& Sons, 2nd Edition, 1990.

[8] A. Mukherrji and R. Karmaakar, Modeling and Simulation of Engiineering Systems through Bondgraphs, Alpha Science International Ltd, 2000.

[9] A. C.Umarikar and L.Umanad, Modelling of switching systems in bondgraaphs using the concept of swithcced power junctions, Journal of the Frankline Institute, Vol. 342, No. 2, pp. 131-147, 2005.

[10] .K. Kazimeirczuk, Modeling Design oriented analysis of boost zerovoltaage switching resonant dc-to-dc converter, IEEE Transactions on Power Electronics, Vol. 3, No. 2, pp. 126-135, 1988.

[11] SShaik Hussain Vali and Ganesh Vulasala, Bond graph modeling and simulation of Boost ZVS Quasiresonant DC-DC power converter, International Journal of recent technology and engineering, Vol. 9, No. 1, pp. 3759-3764, 2019.

[12] Erickkson, RW and Maksimoviic, D, Fundamentals of power electronics, Springer, $3^{\text {rd }}$ Edition, 2001.

[13] Marian Kaziimierczuk and D. Czaarkawski, Resonant power converters, John Wiley \& Sons, $2^{\text {nd }}$ Edition, 2011.

[14] AC. Umarikar, T Mishra and L. Umanand, Modeling Bond graph simulation and symbolic extractiontool box in MATLAB/SIMULINK, Journal of IISc, Vol. 86, No. 1, pp. 45-68, 2006.

\section{Appendix A}

0-junction:

An example bond graph which explains about a 0 -junction is presented in figure 8. The bonds connected to the junction have same effort value. Equations (15) and (16) satisfy the bond graph. Here, flows of the bonds are $\mathrm{f}_{1}-\mathrm{f}_{4}$ where the efforts of the bonds are $\mathrm{e}_{1}-\mathrm{e}_{4}$.

$$
\begin{aligned}
& e_{4}=e_{3}=e_{2}=e_{1} \\
& f_{1}-f_{2}-f_{3}=f_{4}
\end{aligned}
$$

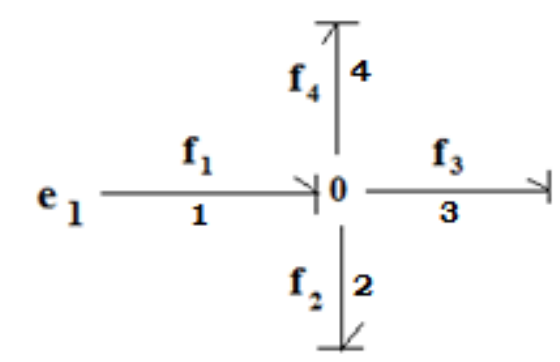

Figure 8. 0 -junction 


\section{1-junction:}

An example bond graph which explains about a 1 -junction is presented in figure 9. The bonds connected to the junction have same flow value. Equations (17) and (18) satisfy the bond graph. Here, flows of the bonds are $\mathrm{f}_{1}-\mathrm{f}_{4}$ where the efforts of the bonds are $\mathrm{e}_{1}-\mathrm{e}_{4}$.

$$
\begin{gathered}
f_{4}=f_{3}=f_{2}=f_{1} \\
e_{1}-e_{2}-e_{3}=e_{4}
\end{gathered}
$$

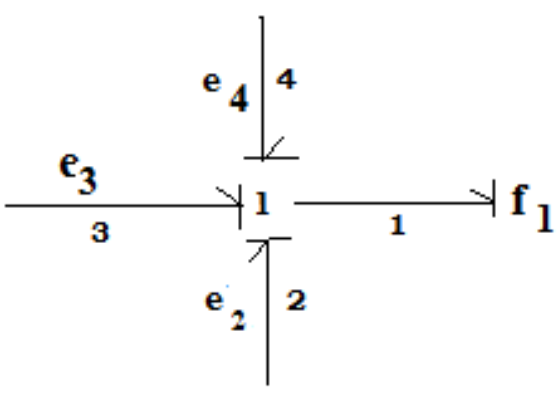

Figure 9. 1-junction

\section{Appendix B}

Os-junction:

An example bond graph with 0s-junction is shown in figure 10. The bond graph has two different states with each effort. Equations (19) and (20) satisfy the bond graph. Here, flows of the bonds are $\mathrm{f}_{1}-\mathrm{f}_{4}$ where the efforts of the bonds are $\mathrm{e}_{1}-\mathrm{e}_{4}$. The states are $\mathrm{U}_{1}$ and $\mathrm{U}_{2}$.

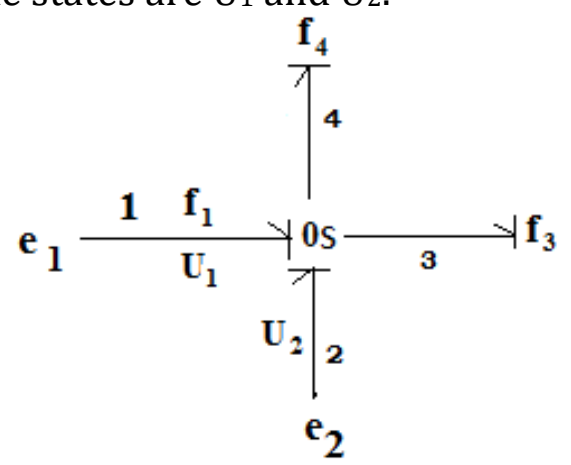

Figure10. 0s-junction

$e_{3}=e_{4}=U_{2} e_{2}+U_{1} e_{1}$

$f_{1}=f_{2}=\left(f_{4}+f_{3}\right) U_{1}$

\section{1s-junction:}

An example bond graph with 1 s-junction is shown in figure 11 . The bond graph has two different states with each flow. Equations (21) and (22) satisfy the bond graph. Here, flows of the bonds are $\mathrm{f}_{1}-\mathrm{f}_{4}$ where the efforts of the bonds are $\mathrm{e}_{1}-\mathrm{e}_{4}$. The states are $\mathrm{U}_{1}$ and $\mathrm{U}_{2}$. 


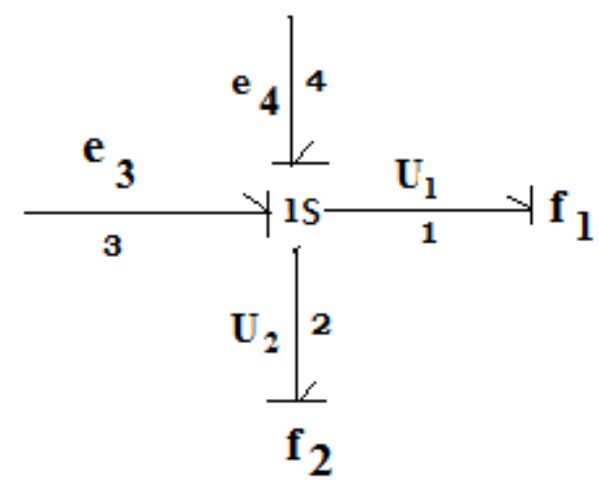

Figure 11. 1s-junction

$$
\begin{aligned}
& f_{3}=f_{4}=U_{1} f_{1}+U_{2} f_{2} \\
& e_{1}=e_{2}=U_{1}\left(e_{3}+e_{4}\right)+U_{2}\left(e_{3}+e_{4}\right)
\end{aligned}
$$

